\title{
Female Urethral Condyloma Causing Bladder Outlet Obstruction
}

\author{
Ji Yun Chae, Jae Hyun Bae ${ }^{1}$, Cheol Yong Yoon, Hong Seok Park, Du Geon Moon, Jeong Gu Lee², Mi Mi Oh \\ Department of Urology, Korea University Guro Hospital, Korea University College of Medicine, Seoul; \\ ${ }^{1}$ Department of Urology, Korea University Ansan Hospital, Korea University College of Medicine, Ansan; \\ ${ }^{2}$ Department of Urology, Korea University Anam Hospital, Korea University College of Medicine, Seoul, Korea
}

\begin{abstract}
In women, urethral condyloma rarely leads to a bladder outlet obstruction. A 39-year-old woman who presented with frequency, urgency, and residual urine sensation was found to have a condyloma in her urethral meatus. Urodynamic study indicated bladder outlet obstruction. After condyloma excision, she returned to normal voiding, and the free maximum flow rate improved. In women, excision of urethral condylomas that cause obstruction can be an effective treatment with early recovery of voiding function.
\end{abstract}

Keywords: Urinary bladder neck obstruction; Condyloma acuminata; Female; Urethra

Condyloma acuminata is often reported to develop in adult anal or genital regions. However, it rarely occurs in the female urethra and seldom causes bladder outlet obstruction (BOO). We report a case of urethral condyloma in a woman who presented BOO-related voiding symptoms.

\section{CASE REPORT}

A 39-year-old woman presented to our hospital complaining of frequency, urgency, and sensation of incomplete bladder emptying. Urinalysis revealed no microscopic hematuria or pyuria, and her urine culture remained sterile. An uroflowmetry was performed, and the free maximum flow rate (Qmax) was low at $14 \mathrm{~mL} / \mathrm{sec}$, with voided volume at $218 \mathrm{~mL}$, and postvoid residual urine volume (PVR) at $25 \mathrm{~mL}$. She was administered an alpha blocker for two weeks, but there was no symptom improvement. A follow-up uroflowmetry showed an even lower Qmax at $8 \mathrm{~mL} / \mathrm{sec}$, with voided volume at $206 \mathrm{~mL}$, and PVR at $45 \mathrm{~mL}$. To rule out any anatomical obstructing lesions, a physical examination was performed, and multiple small papillary masses were noted around the external urethral meatus (Fig. 1).

The rapid plasma reagin card test and Treponema pallidum hemagglutination test results were negative. Cystourethroscopy demonstrated nonspecific findings in the urethra and bladder. An urodynamic study revealed a detrusor pressure at maximum flow rate (PdetQmax) at $25 \mathrm{~cm} \mathrm{H}_{2} \mathrm{O}$ with Qmax at 14 $\mathrm{mL} / \mathrm{sec}$, indicating BOO. The masses were surgically excised, and primary repair was performed. Histopathological examination indicated condyloma acuminata with papillomatosis, acanthosis, parakeratosis, and hyperkeratosis (Fig. 2).

Excision of the masses resulted in near complete resolution of her symptoms. No obvious recurrence of condyloma acuminata has been observed for 6 months after the surgery. One month after the surgical excision, a follow-up uroflowmetry showed an improved Qmax, voided volume, and PVR at $17 \mathrm{~mL} / \mathrm{sec}, 229 \mathrm{~mL}$, and $10 \mathrm{~mL}$, respectively.

\section{DISCUSSION}

There are no absolute criteria to define female $\mathrm{BOO}$ so far, but several reports have indicated that a Qmax less than $15 \mathrm{~mL} / \mathrm{sec}$ combined with a PdetQmax greater than $20 \mathrm{~cm} \mathrm{H}_{2} \mathrm{O}$ in a pressure-flow study is associated with obstructive symptoms [1]. In women, BOO can present with various types of symptoms. Typ-
Corresponding author: $\mathrm{Mi} \mathrm{Mi} \mathrm{Oh}$

Department of Urology, Korea University Guro Hospital, Korea University

College of Medicine, 148 Gurodong-ro, Guro-gu, Seoul 152-703, Korea

Tel: +82-2-2626-3203 / Fax: +82-2-2626-1321 / E-mail: mamah@hanmail.net

Submitted: January 13, 2014 / Accepted after revision: March 3, 2014
This is an Open Access article distributed under the terms of the Creative Commons Attribution Non-Commercial License (http://creativecommons.org/licenses/by-nc/3.0/) which permits unrestricted non-commercial use, distribution, and reproduction in any medium, provided the original work is properly cited. 


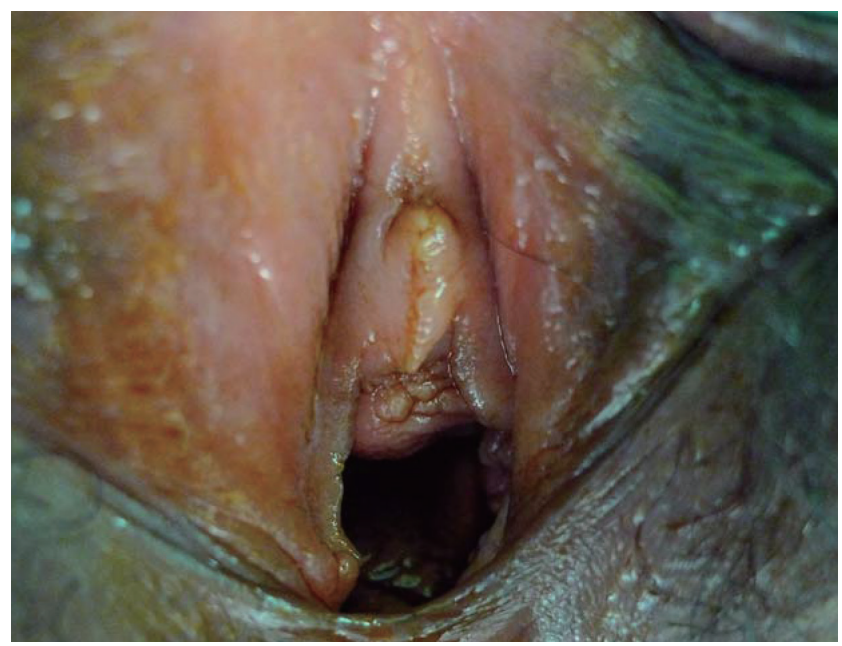

Fig. 1. Urethral condyloma around the female urethra.

ical complaints of slow urinary flow and difficult emptying are highly indicative of BOO. Many other voiding problems such as irritative voiding complaints following $\mathrm{BOO}$ make it more difficult to diagnose [2]. This reinforces the need for a thorough investigation in women with $\mathrm{BOO}$, including careful history taking and physical examination, with other appropriate imaging, functional studies.

The causes of BOO can be classified as anatomical or functional [3]. In women, anatomical causes of BOO include extrinsic compression by Skene's gland cysts, diverticulum, and Gartner's duct remnants. Moreover, genitourinary malignancy including urethral cancer and numerous gynecologic cancers can induce urinary obstruction and should always be considered in the diagnostic algorithm.

Condyloma acuminata is a common sexually transmitted disease caused by the human papillomavirus infection [4]. It is mostly found in young adults between 17-33 years of age, and the incubation period varies from weeks to months [5]. Associated symptoms such as split stream, dysuria, urethral bleeding, and infection are not so common. Condyloma acuminata consists of soft, papillary growths occurring singly or in clusters, and presents in moist areas such as the genitalia, rectum, and urethra. Urethral condyloma is relatively uncommon in both men and women. Even more uncommon is the occurrence of BOO due to urethral condyloma. Various treatment methods have been used, including 5-fluorouracil, interferon, electrocoagulation, cryotherapy, photodynamic therapy, carbon dioxide laser, and local excision. Condyloma treated with electrocoagulation or laser evaporation has high recurrence rates, and urethral ste-

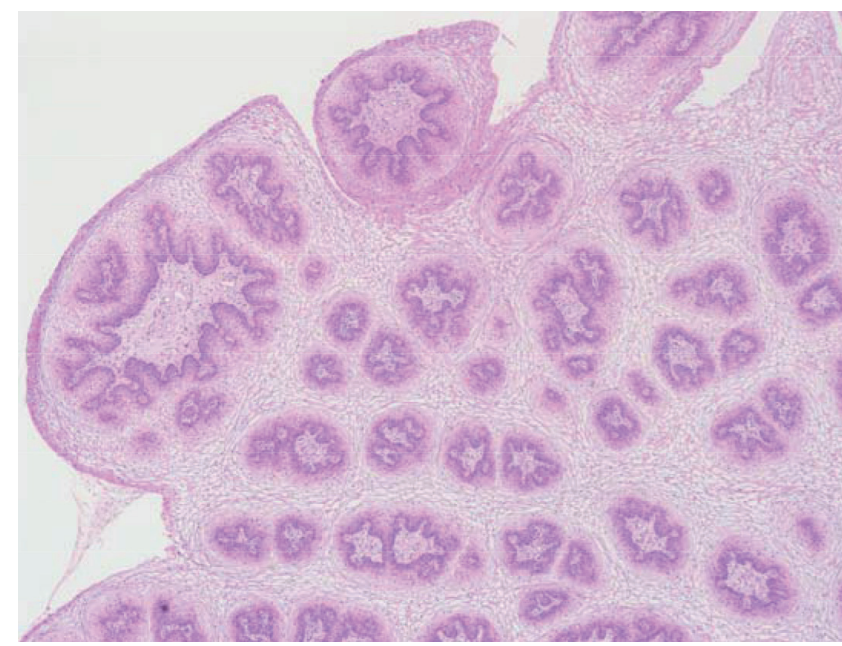

Fig. 2. A villous connective tissue stroma covered by a thickened hyperkeratotic epithelium with hematoxylin and eosin stain $(\times 40)$.

nosis, erosion, and adhesion can occur as complications [6].

In conclusion, female urethral condyloma is a rare entity, and it rarely causes BOO. It should be considered as a differential diagnosis in women presenting with obstructive voiding symptoms associated with a urethral mass. The present case emphasizes that a thorough physical examination should be performed in young women with signs of BOO. In women, excision of urethral condylomas causing obstruction can be an effective treatment with early recovery of voiding function.

\section{CONFLICT OF INTEREST}

No potential conflict of interest relevant to this article was reported.

\section{REFERENCES}

1. Massolt ET, Groen J, Vierhout ME. Application of the Blaivas-Groutz bladder outlet obstruction nomogram in women with urinary incontinence. Neurourol Urodyn 2005;24:237-42.

2. Kaufman MR, Scarpero H, Dmochowski RR. Diagnosis and management of outlet obstruction in the female. Curr Opin Urol 2008; 18:365-9.

3. Goldman HB, Zimmern PE. The treatment of female bladder outlet obstruction. BJU Int 2006;98 Suppl 1:17-23.

4. Scheurer ME, Tortolero-Luna G, Adler-Storthz K. Human papillomavirus infection: biology, epidemiology, and prevention. Int J Gynecol Cancer 2005;15:727-46. 


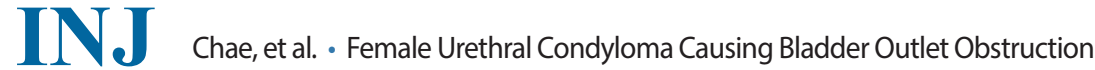

5. Kilciler M, Bedir S, Erdemir F, Coban H, Erten K, Ors O, et al. Condylomata acuminata of external urethral meatus causing infravesical obstruction. Int Urol Nephrol 2007;39:107-9.
6. Fathi R, Tsoukas MM. Genital warts and other HPV infections: Established and novel therapies. Clin Dermatol 2014;32:299-306. 